\title{
A DIMENSIONALITY REDUCTION PRINCIPLE ON THE OPTIMIZATION OF FUNCTION
}

\author{
CHAOBANG GAO AND JIAJIN WEN
}

Abstract. In this paper, we put out a dimensionality reduction principle on the optimization of function, in other words, we show that $\inf _{a \in \mathbb{R}_{+}^{n}}\{f(a)\}=0$ if and only if

$$
\inf _{a \in[0,1]^{m}, k \in K_{m+1}}\left\{f\left(a_{1} I_{k_{1}}, \ldots, a_{m} I_{k_{m}}, I_{k_{m+1}}, O_{n-k_{1}-\cdots-k_{m+1}}\right)\right\}=0
$$

under the proper hypotheses. As applications, we study the optimal problems of linear inequalities involving function power means. In order to show the significance of our results, we give an example for a discrete case by means of the software Mathematica and another example involving space science.

Mathematics subject classification (2010): 26D15, 26E60.

Keywords and phrases: optimization, dimensionality reduction principle, function power mean, $\theta$ average gravity norm.

\section{REFERENCES}

[1] P. S. Bullen, D. S. Mitrinnović, P. M. Vasić, Means and their inequalities, Reidel, Dordrecht/Boston/Lancaster/Tokyo, 1988.

[2] C. GAO, J. WEN, Theories and inequalities on the satellite system, ISRN Mathematical Analysis 2011 (2011), Article ID 909261, 22 pages, doi:10.5402/2011/909261.

[3] C. GaO And J. Wen, Theory of surround system and associated inequalities, Comput. Math. Appl. 63 (2012), 1621-1640.

[4] W.-L. WANG, J. Wen, H. SHI, On the optimal values for inequalities involving power means, Acta. Math. Sinica 47, 6 (2004), 1053-1062.(in Chinese)

[5] J. WEN, W.-L. WANG, Chebyshev type inequalities involving permanents and their applications, Lin. Alg. Appl. 422, 1 (2007), 295-303.

[6] J. WEN AND W.-L. WANG, The optimization for the inequalities of power means, J. Inequlities and Applications 2006 (2006), Article ID 46782, 1-25, DOI 10.1155 /JIA/2006/46782.

[7] J. WEN AND Z. ZHANG, Jensen type inequalities involving homogeneous polynomials, Journal of Inequlities and Applications 2010 (2006), Article ID 850215, 21pages doi:10. 1155/2010/850215.

[8] J. WEN AND W.-L. WANG, The inequalities involving generalized interpolation polynomial, Computers and Mathematics with Applications 56, 4 (2008), 1045-1058.

[9] J. Wen, S. S. Cheng, Closed balls for interpolating quasi-polynomials, Computational and Applied Mathematics 30, 3 (2011), 545-570. 